\title{
Validity of the Stages of Change in Steps instrument (SoC-Step) for achieving the physical activity goal of 10,000 steps per day
}

Richard R. Rosenkranz ${ }^{1,2^{*}}$, Mitch J. Duncan ${ }^{3}$, Cristina M. Caperchione ${ }^{4}$, Gregory S. Kolt ${ }^{2}$, Corneel Vandelanotte ${ }^{5}$, Anthony J. Maeder ${ }^{2}$, Trevor N. Savage ${ }^{2}$ and W. Kerry Mummery ${ }^{6}$

\begin{abstract}
Background: Physical activity (PA) offers numerous benefits to health and well-being, but most adults are not sufficiently physically active to afford such benefits. The 10,000 steps campaign has been a popular and effective approach to promote PA. The Transtheoretical Model posits that individuals have varying levels of readiness for health behavior change, known as Stages of Change (Precontemplation, Contemplation, Preparation, Action, and Maintenance). Few validated assessment instruments are available for determining Stages of Change in relation to the PA goal of 10,000 steps per day. The purpose of this study was to assess the criterion-related validity of the SoC-Step, a brief 10,000 steps per day Stages of Change instrument.

Methods: Participants were 504 Australian adults (176 males, 328 females, mean age $=50.8 \pm 13.0$ years) from the baseline sample of the Walk 2.0 randomized controlled trial. Measures included 7-day accelerometry (Actigraph GT3X), height, weight, and self-reported intention, self-efficacy, and SoC-Step: Stages of Change relative to achieving 10,000 steps per day. Kruskal-Wallis $\mathrm{H}$ tests with pairwise comparisons were used to determine whether participants differed by stage, according to steps per day, general health, body mass index, intention, and selfefficacy to achieve 10,000 steps per day. Binary logistic regression was used to test the hypothesis that participants in Maintenance or Action stages would have greater likelihood of meeting the 10,000 steps goal, in comparison to participants in the other three stages.

Results: Consistent with study hypotheses, participants in Precontemplation had significantly lower intention scores than those in Contemplation ( $p=0.003$ ) or Preparation $(p<0.001)$. Participants in Action or Maintenance stages were more likely to achieve $\geq 10,000$ steps per day $(\mathrm{OR}=3.11 ; 95 \% \mathrm{Cl}=1.66,5.83)$ compared to those in Precontemplation, Contemplation, or Preparation. Intention $(p<0.001)$ and self-efficacy $(p<0.001)$ to achieve 10,000 steps daily differed by stage, and participants in the Maintenance stage had higher general health status and lower body mass index than those in Precontemplation, Contemplation and Preparation stages $(p<0.05)$.
\end{abstract}

Conclusions: This brief SoC-Step instrument appears to have good criterion-related validity for determining Stages of Change related to the public health goal of 10,000 steps per day.

Trial registration: Australian New Zealand Clinical Trials Registry reference: ACTRN12611000157976 World Health Organization Universal Trial Number: U111-1119-1755

Keywords: Motivation, Transtheoretical Model, Targeted intervention, Sedentary lifestyle, Walking, Pedometer

\footnotetext{
* Correspondence: ricardo@ksu.edu

'Kansas State University, Manhattan, USA

${ }^{2}$ Western Sydney University, Sydney, Australia

Full list of author information is available at the end of the article
} 


\section{Background}

Maintaining a physically active lifestyle offers numerous benefits to health and well-being [1]. A large proportion of adults, however, are not sufficiently physically active to afford such benefits [2]. Although physical activity guidelines are typically presented in terms of minutes per week [1], communicating physical activity in terms of steps per day has been offered as an easily understood standard that can be assessed with pedometers or other inexpensive physical activity monitors [3]. Pedometers can be useful tools for motivation, goal setting, and selfmonitoring; a systematic review of physical activity promotion studies employing pedometers showed that their use, within a broader behavior change intervention, was associated with increased physical activity, as well as improvements in blood pressure and body mass index [4].

Many public health interventions have employed pedometers or other step-counters while targeting the promotion of adults' physical activity levels, and 10,000 steps per day campaigns have been popular and effective approaches in these efforts [5-9]. Although the 10,000 steps per day goal is not universally appropriate across various levels of age, gender, and physical function, the goal is deemed to be a reasonable and motivating target for healthy adults [3]. Physical activity intervention studies employing the 10,000 steps per day goal have shown weight loss, improved glucose tolerance, and reduced blood pressure among the outcomes from increased physical activity toward achieving this goal $[10,11]$.

Researchers and public health practitioners have recognized that participants in health promotion programs have varying levels of readiness to undertake potentially challenging lifestyle changes, such as increasing physical activity to a level of 10,000 steps per day [12-16]. Consistent with the Transtheoretical Model [12], interventions can target various subgroups, based on level of readiness for health behavior change, and interventions can be tailored to differing needs or preferences of the participants [13-17]. Studies have shown that such targeted approaches are effective [13], cost-effective $[14,15]$ and often lead to greater improvements in health outcomes compared to non-targeted or non-tailored approaches $[13,16]$.

Tailored interventions are increasingly common, and have shown success in increasing physical activity [13-17]. Few validated assessment instruments are currently available for determining Stages of Change according to the Transtheoretical Model, and none has been based around the 10,000 steps per day public health physical activity goal. The purpose of this study was to assess the criterionrelated validity of a brief 10,000 steps per day Stages of Change in Steps (SoC-Step) instrument. To achieve this, we used baseline data from the Walk 2.0 Study, a 3-arm randomized controlled trial addressing the effects of Web 2.0 applications on engagement, retention, and physical activity behavior change [18].

\section{Hypotheses}

According to the Transtheoretical Model, individuals can be categorized into one of five stages, based on the combination of behavioral intention and previous behavior. Therefore, our main hypothesis testing focused on each of these aspects from the SoC-Step instrument: whether or not participants indicated that they intended to be, and/or indicated currently being, active at a level of taking 10,000 steps per day. Consistent with previous literature [12, 19, 20], it was hypothesized that participants who self-categorized as being in Precontemplation on the SoC-Step instrument would have significantly lower intention scores compared to participants who self-categorized into Contemplation or Preparation stages. Regarding previous behavior, it was hypothesized that those self-categorized into Action and Maintenance stages would have greater levels of accelerometer-measured steps per day, compared to those in Precontemplation, Contemplation, or Preparation stages. In a similar vein, it was hypothesized that if the SoC-Step instrument had good criterion validity, participants in the Action and Maintenance stages, as compared to those in Precontemplation, Contemplation, or Preparation stages, would have significantly higher likelihood to reach the 10,000 steps per day goal.

In addition to the core elements of intention and previous behavior, the Transtheoretical Model suggests that self-efficacy increases as individuals move from Contemplation to Preparation and Action stages. Therefore, we hypothesized that self-efficacy to be physically active at a level of taking 10,000 steps per day would differ among these three stages, with Action showing the highest levels of self-efficacy. Also, given that there is an abundance of literature on the health benefits of regular physical activity [1], we hypothesized that participants in the Maintenance stage would have significantly higher levels of general health and lower body mass index values, as compared to those in Precontemplation, Contemplation, and Preparation.

\section{Methods \\ Participants}

Participants were 504 Australian adults (176 males, 328 females, mean age $=50.8 \pm 13.0$ years) from the baseline sample of the Walk 2.0 randomized controlled trial [18]. This three-arm randomized controlled trial aimed to evaluate the effectiveness of two web-based physical activity interventions, compared to a control group (using a physical activity log book). Both interventions encouraged meeting the 10,000 steps per day goal (or an equivalent level of any physical activity), but also allowed for individual goals above or below that standard. Full 
details of recruitment methods and the study protocol are published elsewhere [18]. The study received ethics approval from the Human Research Ethics Committees of the University of Western Sydney (Reference number H8767) and CQUniversity (H11/01-005).

To be eligible, participants were residents of Western Sydney (New South Wales) or Rockhampton (Queensland), Australia and were able to speak and read English. Eligibility requirements also included: being free of a medical condition which could be exacerbated by physical activity; being over 18 years of age; having access to the Internet but not a member of the website www.10000steps.org.au; and not currently meeting physical activity guidelines, but willing to increase activity levels.

\section{Psychosocial measurement}

The current study draws upon questionnaire data that were obtained from an online survey that participants completed during baseline assessments. The online questionnaire included items and scales from the Transtheoretical Model [12, 20], Social Cognitive Theory [21, 22], and Theory of Planned Behavior [23], all relevant to the 10,000 steps per day goal. From the Transtheoretical Model, Stages of Change were determined using the SoC-Step instrument by asking whether participants were currently taking 10,000 steps per day, how long they had been doing so, or if they were not yet doing so, whether they intended to, or were preparing or beginning to take 10,000 steps per day. The SoC-Step instrument (see Additional file 1) was modelled on a previously published scale [20], but adapted to the 10,000 steps goal for the Walk 2.0 project.

Relevant to Social Cognitive Theory, the online questionnaire included 4 items (on a 0-100 scale; Cronbach's $\alpha=0.848$ ) to assess self-efficacy for physical activity [22] and 10 items (on a 0-100 scale; Cronbach's $\alpha=0.923)$ to assess self-efficacy to overcome common barriers to physical activity [22]. Self-efficacy items required participants to rate their degree of confidence for a set of incremental physical activity behavioral targets (2,000 steps per day; 6,000 steps per day; 10,000 steps per day; 14,000 steps per day) by recording a number from 0 (cannot do at all) to 100 (highly certain can do). Relevant to the Theory of Planned Behavior, the online questionnaire included 2 items (on a 1-5 scale; Cronbach's $\alpha=0.832$ ) on intention and 4 items (on a 1-5 scale; Cronbach's $\alpha=0.772$ ) on attitudes related to being physically active at a level of taking 10,000 steps per day. These were based on a set of previously published items [24], but were modified for Walk 2.0 project needs toward the behavioral goal of 10,000 steps. Intention items rated on a 5-point scale were, "I intend to be physically active at a level of taking 10,000 steps on most days, if not all days of the week, for the next month" and "I will try to be physically active at a level of taking 10,000 steps on most days, if not all days of the week, for the next month."

Other online questionnaire scales included the RAND 36 item Short Form Health Survey (SF-36) to assess quality of life [25]. This instrument covers 8 dimensions of health, including limitations in physical activities and usual role activities due to health problems, bodily pain, general mental health, and vitality (energy and fatigue). The SF-36 has demonstrated adequate validity in Australian populations [26], and is suitable for use in the general population of adults $[27,28]$.

\section{Physical activity monitoring}

Physical activity was assessed with ActiGraph GT3X physical activity monitors (ActiGraph, Shalimar, FL, USA). ActiGraph monitors have demonstrated reliability and validity for the measurement of physical activity, including step counts, in free-living environments [29-31]. Participants were provided with an ActiGraph (fastened to an elastic belt) which they were asked to wear on their right hip. Participants were instructed to wear the ActiGraph continuously for 7 full days during waking hours, unless they planned to swim, bathe, or play contact sports. Participants were asked to complete a physical activity log that was used to record activities undertaken when the ActiGraph was not worn and the duration of non-wear.

ActiGraph data were collected in 1-s epochs, including step counts. When participants returned to complete baseline assessments (at least 8 days after receiving the ActiGraph) the physical data were downloaded and stored. Wear time was assessed using the criteria of $60 \mathrm{~min}$ of consecutive zero data with a 2-min spike tolerance [32]. Minimum valid wear time was set at 600 min of wear time per day across a minimum of 5 days. Participants with insufficient valid wear time were asked to wear the ActiGraph for an additional 7 days. Those not returning an ActiGraph that contained at least minimal valid wear time data in three attempts $(n=39)$ were excluded from analysis. Mean wear time among participants was 867.2 ( $\mathrm{SD}=73.7)$ minutes per day, recorded across 5.9 $(\mathrm{SD}=0.7)$ valid days. Outcome variables for the present study consisted of steps per day (adjusted for total accelerometer wear time), and whether or not the daily step count met the 10,000 steps per day goal.

\section{Anthropometry}

Height, weight, and waist circumference were measured by project staff in a research setting at baseline assessments. Weight was measured in light clothing and without shoes using Seca 700 mechanical scales (Seca Corp., Hamburg, Germany). Height was measured with feet together and head held in the Frankfurt plane, via Seca 220 measuring rod (Seca Corp., Hamburg, 
Germany). Waist circumference was measured using Seca 203 measurement tape (Seca Corp., Hamburg, Germany) at the plane aligned with both iliac crests, in accordance with the National Institutes of Health protocol [33].

\section{Statistical analysis}

All analyses were conducted using SPSS for Windows (Version 22.0), with alpha set at $<0.05$. Variables were checked for normality and other parametric assumptions, and non-parametric tests were used when assumptions were violated. Descriptive statistics included frequencies, percentages, mean, median, standard deviation, and interquartile range.

Independent samples Mann-Whitney or Kruskal Wallis tests (including pairwise comparisons where necessary) were used to test:

1) The hypothesis that participants in Precontemplation would have significantly lower intention scores compared to participants in Contemplation or Preparation stages;

2) The hypothesis that those in Action or Maintenance stages would have greater levels of accelerometer-measured physical activity compared to those in Precontemplation, Contemplation, or Preparation stages;

3) The hypothesis that self-efficacy would differ among Contemplation, Preparation, and Action stages, with Action showing the highest levels of self-efficacy;

4) The hypothesis that participants in the Maintenance stage would have significantly higher levels of general health and lower body mass index values, as compared to those in Precontemplation,

Contemplation, and Preparation stages.

Binary logistic regression, with odds ratios and $95 \%$ confidence intervals, was used to test the hypothesis that participants in Maintenance or Action stages would have greater likelihood of meeting the 10,000 steps goal, in comparison to participants in the other three stages.

\section{Results}

Demographics for the sample are shown in Table 1. Participants comprised mostly middle-aged adults (mean BMI over $29 \mathrm{~kg} / \mathrm{m}^{2}$; mean age around 51 years old); the majority of participants were women (65\%) and were overweight or obese (75\%). More participants were recruited from the Rockhampton area $(n=311)$ than from major metropolitan area of Western Sydney $(n=193)$. The sample was diverse with regard to education, income, employment, and physical activity level, but the
Table 1 Descriptive characteristics of Walk 2.0 study participants

\begin{tabular}{|c|c|c|}
\hline & $N$ & Mean \pm SD \\
\hline Age (years) & 504 & $50.8 \pm 13.1$ \\
\hline Height (m) & 504 & $1.67 \pm 0.09$ \\
\hline Weight (kg) & 504 & $81.8 \pm 18.9$ \\
\hline Body mass index (kg/m2) & 504 & $29.3 \pm 6.0$ \\
\hline Waist circumference $(\mathrm{cm})$ & 504 & $99.9 \pm 15.0$ \\
\hline \multirow[t]{2}{*}{ Physical activity level (unadjusted steps/day) } & 465 & $7,248 \pm 2,424$ \\
\hline & $N$ & Percentage \\
\hline \multicolumn{3}{|l|}{ Sex } \\
\hline Males & 176 & $34.9 \%$ \\
\hline Females & 328 & $65.1 \%$ \\
\hline \multicolumn{3}{|l|}{ Weight Status } \\
\hline Underweight & 6 & $1.2 \%$ \\
\hline Normal weight & 117 & $23.2 \%$ \\
\hline Overweight & 181 & $35.9 \%$ \\
\hline Obese & 200 & $39.7 \%$ \\
\hline \multicolumn{3}{|l|}{ Education } \\
\hline Postgraduate degree & 40 & $7.9 \%$ \\
\hline Graduate certificate or diploma & 38 & $7.5 \%$ \\
\hline Bachelor degree & 93 & $18.5 \%$ \\
\hline Advanced diploma/diploma & 75 & $14.9 \%$ \\
\hline School certificate & 118 & $23.4 \%$ \\
\hline School education & 140 & $27.8 \%$ \\
\hline \multicolumn{3}{|l|}{ Household combined annual income (AUD) } \\
\hline$\$ 0-\$ 41,599$ & 111 & $20.0 \%$ \\
\hline$\$ 41,600-\$ 77,999$ & 117 & $23.2 \%$ \\
\hline$\$ 78,000-\$ 129,999$ & 115 & $22.8 \%$ \\
\hline$\$ 130,000+$ & 103 & $20.4 \%$ \\
\hline Did not report income & 68 & $13.5 \%$ \\
\hline \multicolumn{3}{|l|}{ Area of residence } \\
\hline Sydney area & 193 & $38.3 \%$ \\
\hline Rockhampton area & 311 & $61.7 \%$ \\
\hline \multicolumn{3}{|l|}{ Employment } \\
\hline Full time employment & 234 & $46.4 \%$ \\
\hline Employed part-time/casual & 111 & $22.1 \%$ \\
\hline Retired/Pensioner & 96 & $19.0 \%$ \\
\hline Other & 63 & $12.5 \%$ \\
\hline \multicolumn{3}{|l|}{ Country of birth } \\
\hline Australia & 398 & $79.0 \%$ \\
\hline United Kingdom & 35 & $6.9 \%$ \\
\hline India & 8 & $1.6 \%$ \\
\hline Other & 63 & $12.5 \%$ \\
\hline Speak language other than English at home & 75 & $14.9 \%$ \\
\hline
\end{tabular}


vast majority was born in Australia (79 \%) and spoke English at home (85\%).

Table 2 displays participants' health-related characteristics by Stages of Change. Descriptive statistics include means and standard deviations. Inferential statistics include the Kruskal-Wallis $\mathrm{H}$ test of distributions. These Kruskal-Wallis tests revealed that the distribution of all variables differed among the five Stages of Change $(p<0.05)$. The following are results of the specific tests of our hypotheses used to examine the validity of the SoC-Step instrument.

\section{Intention to be physically active at a level of 10,000 steps per day}

Consistent with hypotheses, there were significant differences in intention scores between non-intenders ("I do NOT intend to be physically active at a level of taking 10,000 steps..." = Precontemplation stage) and those who intended ("I do intend to be physically active at a level of taking 10,000 steps..." = Contemplation and Preparation stages) to be more physically active $(H=70.9, d f=2, p<0.001)$. Specifically, those participants who self-categorized into Precontemplation $($ median $=2.3, \mathrm{IQR}=1.1,3.9$ ), had significantly lower intention scores than those in Contemplation (median $=4.0, \mathrm{IQR}=3.5,4.0 ; H=3.3, d f=1, p=0.003$ ) or Preparation (median $=4.0, \mathrm{IQR}=4.0,5.0 ; H=5.9$, $d f=1, p<0.001)$.
Previous physical activity behavior: accelerometermeasured steps per day

Consistent with study hypotheses, results showed significant differences in accelerometer-measured steps per day between participants who self-categorized into Action or Maintenance stages ("Currently, I take enough steps [10,000 steps per day] to receive health benefits"), and those who self-categorized into Precontemplation, Contemplation, or Preparation ("Currently, I do NOT take enough steps [10,000 steps per day] to receive health benefits.") stages (U $=17,273$, $d f=1, p<0.001)$. Specifically, those participants who self-categorized into Action or Maintenance stages (median $=7,654, \mathrm{IQR}=6,386,10,172$ ), had significantly higher step counts than those in Contemplation or Preparation (median for "intenders" $=6,724$, IQR $=$ $5,594,8,295 ; H=68.2, d f=1, p<0.001)$ but not Precontemplation (median for "non-intenders" $=6,222$; $\mathrm{IQR}=4,863,9,605 ; H=83.1, d f=1, p=0.124$ ).

Also consistent with the study hypothesis, analysis revealed that those in Action or Maintenance stages were more likely to achieve 10,000 steps per day, as compared to those in Precontemplation, Contemplation, or Preparation stages (27 vs. $11 \%$ of participants meeting the 10,000 steps goal; $\mathrm{OR}=3.11 ; 95 \% \mathrm{CI}=1.66,5.83, p<0.001$ ).

\section{Physical activity self-efficacy}

Figure 1 shows self-efficacy to achieve 10,000 steps per day by Stages of Change. The stages differed in measures

Table 2 Participants' health-related variables by Stages of Change $(n=506)$

\begin{tabular}{|c|c|c|c|c|c|c|}
\hline & $\begin{array}{l}\text { Precontemplation } \\
n=16 \\
\text { Mean } \pm \text { SD }\end{array}$ & $\begin{array}{l}\text { Contemplation } \\
n=201 \\
\text { Mean } \pm \text { SD }\end{array}$ & $\begin{array}{l}\text { Preparation } \\
n=214 \\
\text { Mean } \pm \text { SD }\end{array}$ & $\begin{array}{l}\text { Action } \\
n=13 \\
\text { Mean } \pm \text { SD }\end{array}$ & $\begin{array}{l}\text { Maintenance } \\
n=60 \\
\text { Mean } \pm \text { SD }\end{array}$ & $p$-value ${ }^{a}$ \\
\hline Steps per day ${ }^{b}$ & $7,147 \pm 3,166$ & $6,998 \pm 2,119$ & $7,077 \pm 2,210$ & $7,864 \pm 2,550$ & $8,464 \pm 2,917$ & $p=0.015$ \\
\hline Waist circumference & $102.7 \pm 13.5$ & $100.6 \pm 14.8$ & $101.3 \pm 15.2$ & $100.5 \pm 17.5$ & $91.8 \pm 12.8$ & $p<0.001$ \\
\hline Body mass index & $30.7 \pm 5.5$ & $29.7 \pm 6.1$ & $29.9 \pm 6.0$ & $28.3 \pm 4.8$ & $25.2 \pm 4.1$ & $p<0.001$ \\
\hline Intention & $2.5 \pm 1.3$ & $3.8 \pm 0.7$ & $4.3 \pm 0.6$ & $4.0 \pm 0.7$ & $4.4 \pm 0.6$ & $p<0.001$ \\
\hline Self-efficacy PA & $6.2 \pm 2.8$ & $8.1 \pm 1.8$ & $8.9 \pm 1.6$ & $9.9 \pm 0.8$ & $10.0 \pm 1.1$ & $p<0.001$ \\
\hline Self-efficacy barriers to PA & $5.1 \pm 2.4$ & $6.5 \pm 1.9$ & $7.0 \pm 1.9$ & $7.5 \pm 1.9$ & $7.8 \pm 1.6$ & $p<0.001$ \\
\hline Attitudes & $3.1 \pm 1.0$ & $4.0 \pm 0.5$ & $4.1 \pm 0.5$ & $4.1 \pm 0.6$ & $4.1 \pm 0.7$ & $p<0.001$ \\
\hline Physical functioning & $76.3 \pm 27.2$ & $82.6 \pm 18.2$ & $85.9 \pm 15.0$ & $87.3 \pm 17.5$ & $94.8 \pm 7.9$ & $p<0.001$ \\
\hline Role physical & $68.8 \pm 38.2$ & $78.7 \pm 34.5$ & $82.8 \pm 30.5$ & $76.9 \pm 33.0$ & $92.9 \pm 16.7$ & $p=0.035$ \\
\hline Energy fatigue & $52.8 \pm 17.9$ & $53.2 \pm 18.8$ & $55.7 \pm 20.5$ & $66.2 \pm 15.6$ & $64.7 \pm 18.7$ & $p=0.001$ \\
\hline Emotional wellbeing & $68.3 \pm 19.8$ & $75.4 \pm 16.5$ & $78.7 \pm 14.8$ & $78.8 \pm 14.5$ & $81.1 \pm 13.8$ & $p=0.041$ \\
\hline Role emotional & $56.3 \pm 48.3$ & $78.3 \pm 33.6$ & $82.9 \pm 30.6$ & $87.2 \pm 32.0$ & $87.8 \pm 28.1$ & $p=0.021$ \\
\hline Social functioning & $77.3 \pm 25.1$ & $85.1 \pm 19.0$ & $86.7 \pm 19.0$ & $81.7 \pm 22.6$ & $91.3 \pm 17.0$ & $p=0.033$ \\
\hline Pain score & $72.7 \pm 27.4$ & $78.0 \pm 20.9$ & $77.7 \pm 21.9$ & $72.3 \pm 29.8$ & $87.6 \pm 15.0$ & $p=0.015$ \\
\hline General health & $50.9 \pm 16.1$ & $62.0 \pm 19.9$ & $63.6 \pm 20.0$ & $68.8 \pm 11.9$ & $79.1 \pm 15.0$ & $p<0.001$ \\
\hline
\end{tabular}

Note: Means and SD shown for descriptive purposes

${ }^{a}$ Exact $p$ value is from Kruskal-Wallis test of overall difference among Stages of Change distributions (not based on means, due to data skewness)

${ }^{\mathrm{b}} \mathrm{Steps}$ per day adjusted for total accelerometer wear time 


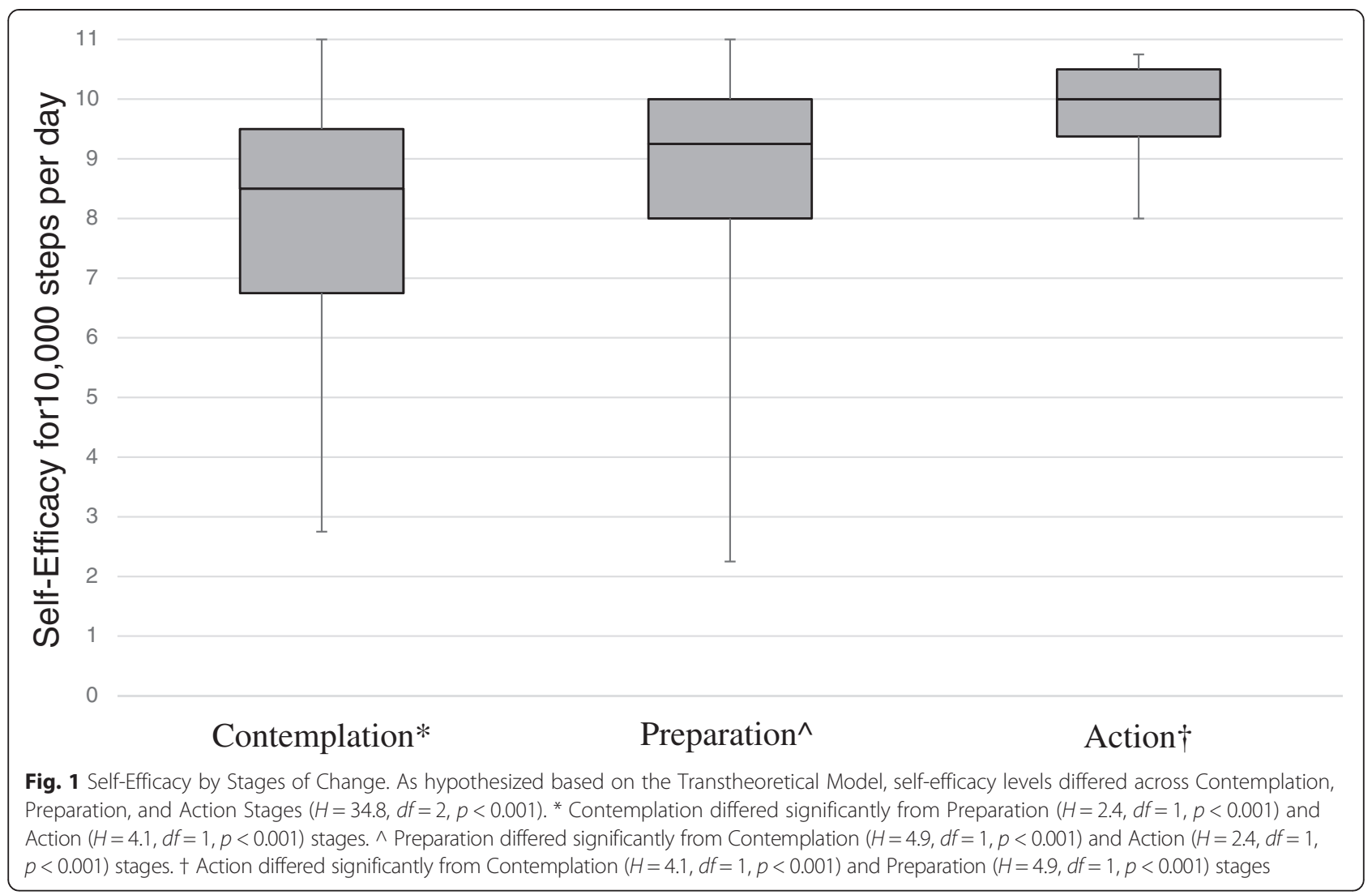

of self-efficacy to achieve 10,000 steps per day $(H=34.8$, $d f=2, p<0.001)$. As hypothesized, pairwise comparisons showed that Action participants (median $=10.0$; IQR $=9.4$, 10.5) had significantly higher self-efficacy to achieve 10,000 steps per day than those in Contemplation (median $=8.5$; $\mathrm{IQR}=6.8,9.5 ; H=4.1, d f=1, p<0.001$ ), or Preparation ( median = 9.3; IQR = 8.0, 10.0; $H=2.4, d f=1, p<0.001$ ). Preparation stage participants also had significantly greater self-efficacy than those in Contemplation $(H=$ 4.9, $d f=1, p<0.001)$.

Similarly, stages differed in measures of self-efficacy to overcome common barriers to physical activity $(H=8.4$, $d f=2, p=0.015)$. As hypothesized, pairwise comparisons showed that Preparation stage (median $=7.1 ; \mathrm{IQR}=5.7$, 8.5) participants had higher self-efficacy than those in Contemplation $($ median $=6.4 ; \mathrm{IQR}=5.3,7.9 ; H=2.5, d f=1$, $p<0.035$ ). Action stage participants (median $=7.1$; IQR $=$ $6.5,8.9)$, however, did not differ significantly from those in Preparation $(H=1.8, d f=1, p=0.196)$ or Contemplation stages $(H=0.9, d f=1, p=0.983)$

\section{Body mass index and self-reported general health}

Figure 2 displays median body mass index, and Fig. 3 shows self-reported general health values, across the five stages of change. Analyses showed that there was a significant difference across stages for body mass index
( $H=24.2, d f=4, p<0.001)$, as well as for general health $(H=31.2, d f=4, p<0.001)$.

Consistent with hypotheses, those in Maintenance stage ( median $=24.7 \mathrm{~kg} / \mathrm{m}^{2}, \mathrm{IQR}=22.6,27.8$ ) had lower body mass index values than participants in Precontemplation (median $=32.7 \mathrm{~kg} / \mathrm{m}^{2}, \mathrm{IQR}=27.1,34.6 ; H=3.9, d f=1$, $p=0.001$ ), Contemplation (median $=28.8 \mathrm{~kg} / \mathrm{m}^{2}, \mathrm{IQR}=$ 25.4, 33.3; $H=5.6, d f=1, p<0.001)$, and Preparation stages $\left(\right.$ median $=29.0 \mathrm{~kg} / \mathrm{m}^{2}, \mathrm{IQR}=25.9,33.3 ; H=5.8$, $d f=1, p<0.001)$. Participants in the Maintenance stage were not significantly different from those in Action stage for body mass index or general health $(p>0.05)$.

As hypothesized, participants in the Maintenance stage $($ median $=80.0, \mathrm{IQR}=70.0,90.0)$ reported better general health than their counterparts in Precontemplation (median $=55.0, \mathrm{IQR}=45.0,58.8 ; H=5.4, d f=1$, $p<0.001$ ), Contemplation (median $=65.0, \mathrm{IQR}=50.0$, 75.0; $H=6.1, d f=1, p<0.001)$, and Preparation stages (median = 70.0, $\mathrm{IQR}=50.0,80.0 ; H=5.4, d f=1, p<0.001$ ).

\section{Discussion}

This study used the baseline questionnaire, activity monitor, and anthropometric data from the Walk 2.0 Study to assess the criterion-related validity of a brief 10,000 steps per day Stages of Change (SoC-Step) instrument, and found substantial evidence for its validity. As hypothesized in 


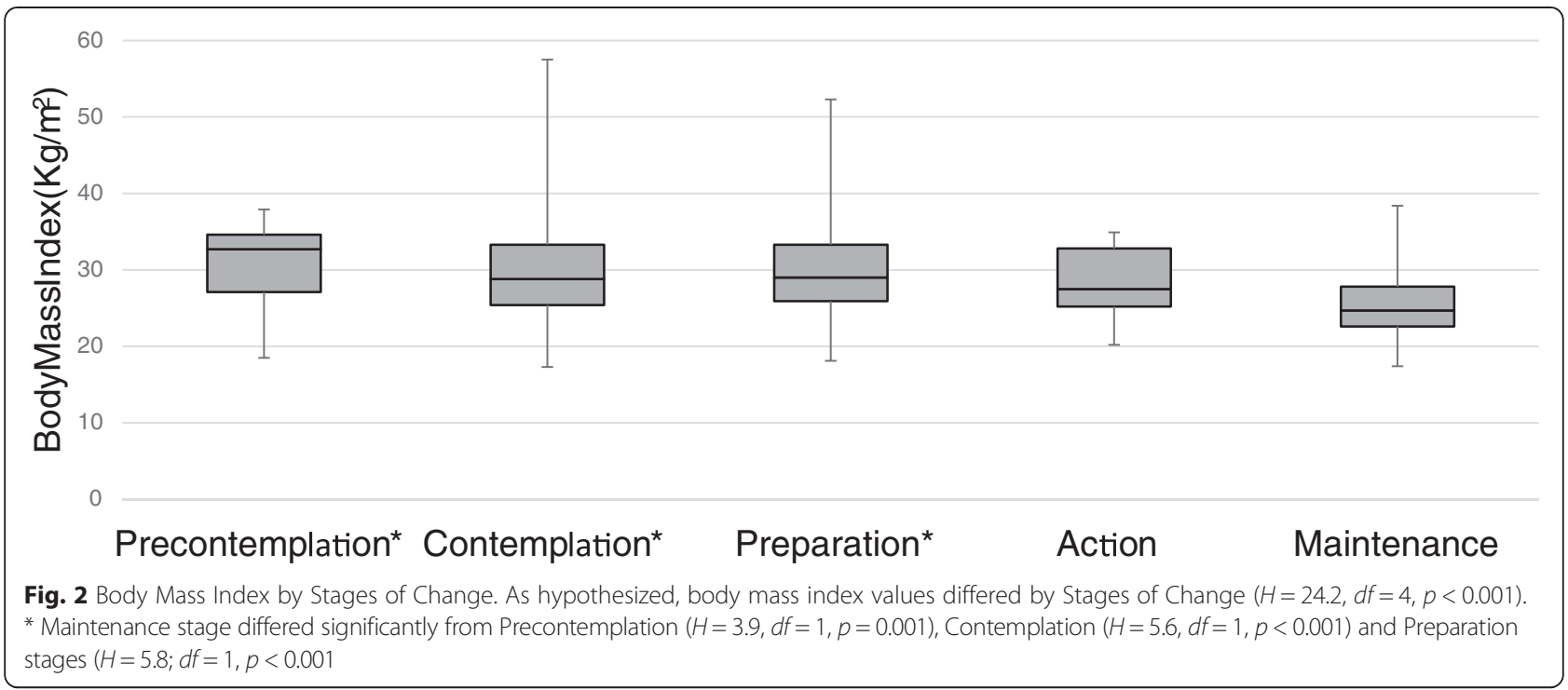

accordance with the Transtheoretical Model, there were significant differences among the Stages of Change in steps per day, in likelihood of meeting the 10,000 steps per day goal, and in intention and self-efficacy related to achieving 10,000 steps per day.

According to Devon and colleagues [34], criterionrelated validity is evidenced by the relationship between the characteristics of a measurement instrument and performance on another performance measurement. Concurrent criterion-related validity refers to the correspondence between scores from two instruments that were measured at the same point in time [34]. A measure achieves its degree of criterion validity (also known as empirical or statistical validity) to the extent that it corresponds with another observation that accurately measures the variable under study [35].

One key element of the SoC-Step instrument is the reported intention to "be physically active at a level of taking 10,000 steps or more on most days, if not all days of the week." The Theory of Planned Behavior two-item scale of intention scores provided a concurrent measure of this construct. Consistent with theory, these intention scores varied as a function of the Stages of Change in the hypothesized direction, such that Precontemplation stage participants had lower levels of intention than those in Contemplation or Preparation. These findings support the concurrent validity of SoC-Step with regard to intention to meet the 10,000 steps per day standard.

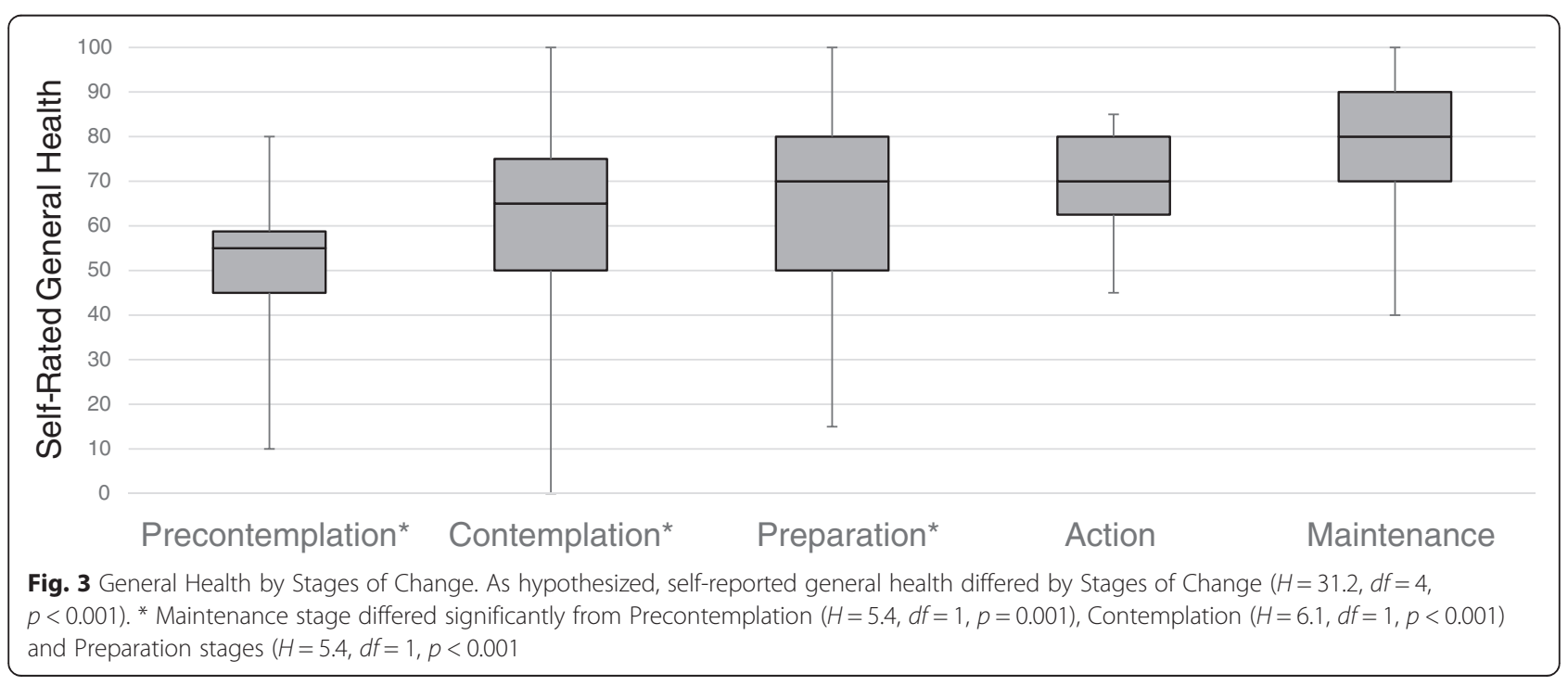


In the present study, our criterion of physical activity was the daily step count obtained from ActiGraph activity monitors. The Stages of Change measure was significantly related to daily step count, as hypothesized. Most germane to the issue, those participants who indicated that, "Currently, I take enough steps (10,000 steps per day) to receive health benefits," on the SoC-Step instrument (i.e., those classified in Action or Maintenance stages) had the highest step counts, as well as the highest likelihood of meeting the 10,000 steps per day standard. Together, these findings suggest that the SoC-Step instrument shows good concurrent validity with the Actigraph physical activity monitor criterion variable.

Self-efficacy is a central construct within both Social Cognitive Theory and the Transtheoretical Model. As hypothesized, the measures of physical activity self-efficacy pertaining to participants' confidence to achieve varying levels of steps per day varied as a function of Stages of Change. The measure of self-efficacy pertaining to participants' confidence to be active when faced with various challenges (self-efficacy to overcome common barriers to physical activity) was also related to Stages of Change in the hypothesized manner, although Action stage participants were not significantly different from those in Contemplation or Preparation (possibly due to the small number in Action stage). Overall, these findings provide further evidence for the criterion-related validity of the brief SoC-Step instrument.

The evidence for validity of the investigated SoC-Step instrument parallels that of other researchers who have previously developed and validated brief Stages of Change instruments [19, 20, 36-38]. The present instrument, however, is unique in its focus on the 10,000 steps goal. Reed and colleagues [37] investigated various algorithms to ascertain optimal characteristics of staging regular exercise behavior. These authors found that precise definitions of exercise, including all parameters needed to meet a criterion, were helpful to participants who were assessing themselves relative to a stage of change [37]. Furthermore, a five-choice format was endorsed as effective in assessing stage. The present study's instrument conforms with these recommendations, in that extensive information with a precise behavioral definition is provided to the participant, along with a five-choice response format. The presence of such recommended characteristics may partially explain the substantial concordance observed between the SoCStep and the criterion measure.

The observed relationships between stage classification and health are similar to systematic review findings by Bize et al. [39], along with those of Laforge et al. [40], who found that exercise stage was associated with selfperceived quality of life. In particular, Laforge et al. found that general health was lowest in Precontemplation, and highest in the Maintenance stage. Similarly, Cardinal and colleagues [36] found a relationship between Stages of Change in exercise and body mass index. The present study, however, is unique in its framing of Stages of Change around a public health physical activity goal, and in using additional objective health-related comparisons such as activity monitor data and clinically measured body mass index.

One limitation with regard to validity of this instrument was observed in that many participants who categorized themselves in Action or Maintenance stages for a physical activity level of 10,000 steps per day did not meet this standard based on objectively measured accelerometer data. It is important to note, however, that accelerometers do not capture all types of physical activity, and may provide a conservative estimate of step counts in some cases [31, 41]. In addition, our reliance on self-report instruments for both Stages of Change and intention may result in bias associated with common method variance, although undertaking measurement of participant intention without reliance on self-report would likely present alternate forms of bias.

Another limitation is the small number of participants classified in Precontemplation, which then hindered our ability to detect differences in relevant pairwise comparisons, due to low power. Having small numbers in Precontemplation is expected here, however, given that our study sample comprised those successfully recruited to a behavior change study. Although it may appear incongruous that participants recruited into a physical activity promotion study could classified in the Precontemplation stage, there are two issues to consider: 1) Stages of Change is specific to a target behavior [12], and while our behavioral target was 10,000 steps daily (at any intensity) for categorizing participants, they were originally included in the intervention if they "were currently engaging in less than a half an hour (30 $\mathrm{min}$ ) of moderate-to-vigorous (e.g., walking, running or playing sport) physical activity on five or more days of the week;" 2) Stages of Change suggests that participants frequently regress into earlier stages [12], and that could have been a factor in the present study. Last, our sample was delimited to middle-aged Australians from two regions participating in an intervention (predominantly female, mostly overweight and obese, of a narrow age range, and mostly categorized in contemplation and preparation stages), so our findings may not apply to demographically different populations. Future studies should assess validity of the SoC-Step Instrument in younger adults.

Despite the aforementioned limitations, the present study possessed a number of strengths, including a large and diverse sample of middle-aged Australian adults who may represent a larger population of those who would be willing to participate in public health physical activity interventions. These participants provided not only self- 
report data, but also objective measures of physical activity and body mass index, which contribute to the rigor of this study's methods.

\section{Conclusions}

In this study, a cohort of mostly middle-aged, overweight and obese, Australian adults showed variations in objectively measured steps, body mass index, selfreported intention, and self-efficacy, as a function of self-reported Stages of Change toward the public health goal of achieving 10,000 steps daily. These variations corresponded with the hypotheses derived from the Transtheoretical Model, and thereby provided support for the criterion-related validity of the SoC-Step instrument. This brief instrument appears to have good criterion-related validity for determining Stages of Change related to the public health goal of 10,000 steps, and could be useful in tailored intervention efforts that could help lead to improvements in health-related quality of life.

\section{Additional file}

Additional file 1: The SoC-Step, a Stages of Change instrument relevant to the physical activity goal of 10,000 steps per day. (PDF $175 \mathrm{~kb}$ )

\section{Abbreviations}

SoC-Step: The Stages of Change in Steps instrument related to 10,000 steps per day; SF-36: Short Form Health Survey.

\section{Competing interests}

The authors declare that they have no competing interests.

\section{Authors' contributions}

RRR conceived of the study, analyzed data, and wrote the first draft of the manuscript. WKM, GSK, AJM, CV, MJD, and CMC conceived the Walk 2.0 Project and procured the project funding. GSK led the coordination of the trial. TNS managed the project, including data collection. AJM developed the IT platform for the project. All authors read, edited, and approved the final manuscript.

\section{Acknowledgements}

This trial is being funded by the National Health and Medical Research Council (Project Grant number 589903). The funder does not have any role in the study other than to provide funding. CV was supported by a National Health and Medical Research Council (\#519778) and National Heart Foundation of Australia (\#PH 07B 3303) post-doctoral research fellowship during the conception of the research project and recruitment. CV is currently supported by a Future Leader Fellowship (ID 100427) from the National Heart Foundation of Australia. MJD is supported by a Future Leader Fellowship (ID 100029) from the National Heart Foundation of Australia. Publication of this article was funded in part by the Kansas State University Open Access Publishing Fund.

\section{Author details}

${ }^{1}$ Kansas State University, Manhattan, USA. ${ }^{2}$ Western Sydney University, Sydney, Australia. ${ }^{3}$ University of Newcastle, Newcastle, Australia. ${ }^{4}$ University of British Columbia, Kelowna, Canada. ${ }^{5}$ Central Queensland University, Rockhampton, Australia. ${ }^{6}$ University of Alberta, Edmonton, AB, Canada.

Received: 18 February 2015 Accepted: 23 November 2015

Published online: 30 November 2015

\section{References}

1. US Department of Health and Human Services (USDHHS). Physical Activity Guidelines Advisory Committee Report, Washington, DC; 2008.

2. Hallal PC, Andersen LB, Bull FC, Guthold R, Haskell W, Ekelund U. Global physical activity levels: surveillance progress, pitfalls, and prospects. Lancet. 2012;380:247-57.

3. Tudor-Locke C, Craig CL, Brown WJ, Clemes SA, De Cocker K, Giles-Corti B, et al. How many steps/day are enough? For adults. Int J Behav Nutr Phys Act. 2011;8:79.

4. Bravata DM, Smith-Spangler C, Sundaram V, Gienger AL, Lin N, Lewis R, et al. Using pedometers to increase physical activity and improve health: a systematic review. JAMA. 2007;298:2296-304

5. Brown WJ, Mummery WK, Eakin E, Schofield G. 10,000 Steps Rockhampton: evaluation of a whole community approach to improving population levels of physical activity. J Phys Act Health. 2006;3:1-14.

6. De Cocker KA, De Bourdeaudhuij IM, Brown WJ, Cardon GM. Effects of "10,000 steps Ghent": a whole-community intervention. Am J Prev Med. 2007;33:455-63.

7. Davies C, Corry K, Van Itallie A, Vandelanotte C, Caperchione C, Mummery WK. Prospective associations between intervention components and website engagement in a publicly available physical activity website: the case of 10,000 steps Australia. J Med Internet Res. 2012;14:e4.

8. Mummery WK, Schofield G, Hinchliffe A, Joyner K, Brown W. Dissemination of a community-based physical activity project: the case of 10,000 steps. J Sci Med Sport. 2006;9:424-30.

9. Brown W, Eakin E, Mummery WK, Trost S. 10,000 Steps Rockhampton: establishing a multi-strategy physical activity promotion project in a community. Health Promot J Austr. 2003;14:95-100.

10. Schneider PL, Bassett Jr DR, Thompson DL, Pronk NP, Bielak KM. Effects of a 10,000 steps per day goal in overweight adults. Am J Health Prom. 2006;21: $85-9$.

11. Swartz AM, Strath SJ, Bassett Jr DR, Moore JB, Redwine BA, Groër M, et al. Increasing daily walking improves glucose tolerance in overweight women. Prev Med. 2003;37:356-62.

12. Prochaska JO, DiClemente CC. Toward a comprehensive model of change. In: Miller WR, Heather N, editors. Treating Addictive Behaviors: Processes of Change. 1st ed. New York: Plenum Press; 1986. p. 3-27.

13. Krebs P, Prochaska JO, Rossi JS. A meta-analysis of computer-tailored interventions for health behaviour change. Prev Med. 2010;51:214-21.

14. Golsteijn RH, Peels DA, Evers SMAA, Bolman C, Mudde AN, et al. Costeffectiveness and cost-utility of a Web-based or print-delivered tailored intervention to promote physical activity among adults aged over fifty: an economic evaluation of the Active Plus intervention. Int J Behav Nutr Phys Act. 2014;11:10-1186.

15. Van Keulen H, Bosman J, van Tulder M, Severens J, de Vries H, Brug J, et al. Cost-effectiveness of tailored print communication, telephone motivational interviewing, and a combination of the two: results of an economic evaluation alongside the Vitalum randomized controlled trial. Int J Behav Nutr Phys Act. 2010;7:64.

16. Lustria MLA, Noar SM, Cortese J, Van Stee SK, Glueckauf RL, Lee J. A meta-analysis of web-delivered tailored health behavior change interventions. J Health Comm. 2013;18:1039-69.

17. Peels DA, Bolman C, Golsteijn RHJ, De Vries H, Mudde AN, Van Stralen MM, et al. Long-term efficacy of a tailored physical activity intervention among older adults. Int J Behav Nutr Phys Act. 2013;10:104.

18. Kolt GS, Rosenkranz RR, Savage TN, Maeder AJ, Vandelanotte C, Duncan MJ, et al. WALK 2.0-using Web 2.0 applications to promote health-related physical activity: a randomised controlled trial protocol. BMC Public Health. 2013;13:436.

19. Lippke S, Fleig L, Pomp S, Schwarzer R. Validity of a stage algorithm for physical activity in participants recruited from orthopedic and cardiac rehabilitation clinics. Rehab Psych. 2010;55:398-408.

20. Ronda G, Van Assema P, Brug J. Stages of change, psychological factors and awareness of physical activity levels in the Netherlands. Health Promot Int. 2001;16:305-14.

21. Bandura A. Social foundations of thought and action: a social cognitive theory. Englewood Cliffs, NJ: Prentice-Hall; 1986.

22. Bandura A. Guide for constructing self-efficacy scales. In: Pajares F, Urdan TC, editors. Self-Efficacy Beliefs of Adolescents. Volume 5. Greenwich: Information Age Publishing; 2006.

23. Ajzen I. The theory of planned behavior. Organ Behav Hum. 1991;50: $179-211$. 
24. Caperchione CM, Duncan MJ, Mummery WK, Steele R, Schofield G. Mediating relationship between body mass index and the direct measures of the theory of planned behaviour on physical activity intention. Psychol Health Med. 2008;13:168-79.

25. Ware Jr JE, Sherbourne CD. The MOS 36-item short-form health survey (SF-36): I. Conceptual framework and item selection. Med Care. 1992;30: 473-83.

26. McCallum J. The SF-36 in an Australian sample: validating a new, generic health status measure. Aust J Public Health. 1995;19:160-6.

27. Stevenson C. SF-36: Interim Norms for Australian Data. Australia: Australian Institute of Health and Welfare; 1996.

28. Australian Bureau of Statistics. National health survey: SF-36 population norms: Australia. Canberra: ABS; 1995.

29. Sasaki JE, John D, Freedson PS. Validation and comparison of ActiGraph activity monitors. J Sci Med Sport. 2011;14:411-6.

30. Vanhelst J, Mikulovic J, Bui-Xuan G, Dieu O, Blondeau T, Fardy P, et al. Comparison of two ActiGraph accelerometer generations in the assessment of physical activity in free living conditions. BMC Res Notes. 2012;5:187.

31. Esliger DW, Probert A, Connor GS, Bryan S, Laviolette M, Tremblay MS. Validity of the Actical accelerometer step-count function. Med Sci Sports Exerc. 2007;39:1200-4.

32. Healy GN, Matthews CE, Dunstan DW, Winkler EA, Owen N. Sedentary time and cardiometabolic biomarkers in US adults: NHANES 2003-06. Eur Heart J. 2011;32:590-7.

33. NHLBI Obesity Education Initiative Expert Panel. Treatment guidelines. In Clinical Guidelines on the Identification, Evaluation, and Treatment of Overweight and Obesity in Adults - the Evidence Report. Washington D.C. National Institutes of Health; 1998. p. 56-94.

34. DeVon HA, Block ME, Moyle-Wright P, Ernst DM, Hayden SJ, Lazzara DJ et al. A psychometric toolbox for testing validity and reliability. J Nurs Scholarship. 2007:39:155-64.

35. Kaplan RM, Bush JW, Berry CC. Health status: types of validity and the index of well-being. Health Serv Res. 1976;11:478.

36. Cardinal BJ. Construct validity of stages of change for exercise behavior. Am J Health Prom. 1997;12:68-74

37. Reed GR, Velicer WF, Prochaska JO, Rossi JS, Marcus BH. What makes a good staging algorithm: examples from regular exercise. Am J Health Prom. 1997; 12:57-66.

38. Marttila J, Nupponen R. Assessing stage of change for physical activity: how congruent are parallel methods? Health Educ Res. 2003;18:419-28.

39. Bize R, Johnson JA, Plotnikoff RC. Physical activity level and health-related quality of life in the general adult population: a systematic review. Prev Med. 2007;45:401-15

40. Laforge RG, Rossi JS, Prochaska JO, Velicer WF, Levesque DA, McHorney CA Stage of regular exercise and health-related quality of life. Prev Med. 1999; 28:349-60.

41. Rosenkranz RR, Rosenkranz SK, Weber C. Validity of the Actical accelerometer step-count function in children. Ped Exerc Sci. 2011:23:355.

\section{Submit your next manuscript to BioMed Central and we will help you at every step:}

- We accept pre-submission inquiries

- Our selector tool helps you to find the most relevant journal

- We provide round the clock customer support

- Convenient online submission

- Thorough peer review

- Inclusion in PubMed and all major indexing services

- Maximum visibility for your research

Submit your manuscript at www biomedcentral com/submit 